\title{
Inhibition of toll-like receptor 2 expression improves insulin sensitivity and signaling in muscle and white adipose tissue of mice fed a high-fat diet
}

\author{
Andréa M Caricilli, Paula H Nascimento, José R Pauli, Daniela M L Tsukumo, Lício A Velloso, \\ José B Carvalheira and Mário J A Saad \\ Department of Internal Medicine, State University of Campinas, 13081-970 Campinas, SP, Brazil \\ (Correspondence should be addressed to M J A Saad who is now at Departamento de Clínica Médica, FCM-UNICAMP, Cidade Universitária Zeferino Vaz, \\ 13081-970 Campinas, SP, Brazil; Email: msaad@fcm.unicamp.br)
}

\begin{abstract}
The aims of the present study were to investigate the expression of toll-like receptor 2 (TLR2) in muscle and white adipose tissue (WAT) of diet-induced obesity (DIO) mice, and also the effects of its inhibition, with the use of TLR 2 antisense oligonucleotide (ASON), on insulin sensitivity and signaling. The expression of TLR2 was increased in muscle and WAT of DIO mice, compared with those that received standard chow. Inhibition of TLR2 in DIO mice, by TLR2 ASON, improved insulin sensitivity and signaling in muscle and WAT. In addition, data
\end{abstract}

show that the inhibition of TLR2 expression prevents the activation of IKBKB, MAPK8, and serine phosphorylation of IRS1 in DIO mice, suggesting that TLR2 is a key modulator of the crosstalk between inflammatory and metabolic pathways. We, therefore, suggest that a selective interference with TLR2 presents an attractive opportunity for the treatment of insulin resistance in obesity and type 2 diabetes.

Journal of Endocrinology (2008) 199, 399-406

\section{Introduction}

Obesity is associated with insulin resistance and a state of abnormal inflammatory response (Kadowaki et al. 2003, Bray 2004, Tsukumo et al. 2007). There is convincing evidence that the activation of the MAPK8, IKK, and NOS2 (Perreault \& Marette 2001, Yuan et al. 2001, Hirosumi et al. 2002, Lee et al. 2003, Carvalho-Filho et al. 2005) pathways is related to the reduction in insulin sensitivity, but it has only recently been shown that these pathways may be integrated to cause insulin resistance by the activation of membrane receptors, such as toll-like receptors (TLRs; Aderem \& Ulevitch 2000, Shi et al. 2006, Tsukumo et al. 2007).

There are at least 11 members of the TLR family in humans and 13 in mice (Takeda \& Akira 2004). TLRs play a crucial role in the recognition of invading pathogens and the activation of subsequent immune responses against them. Individual TLRs recognize distinct pathogen-associated molecular patterns. The TLR family harbors an extracellular leucine-rich repeat domain, as well as a cytoplasmic domain that is homologous to that of the interleukin-1 receptor (IL1R1). Upon stimulation, TLR recruits IL1R1-associated protein kinases via adaptor MYD88, and finally induces the activation of nuclear factor- $\mathrm{\kappa B}$ and mitogen-activated protein kinases, as well as the expression of inflammatory cytokines (Aderem \& Ulevitch 2000, Heldwein \& Fenton 2002,
Akira \& Sato 2003). Preliminary studies have indicated that loss-of-function mutation and knockout in TLR 4 prevents insulin resistance induced by obesity or free fatty acids, suggesting an important role of TLR 4 in the interface of innate immune system and energetic metabolism (Shi et al. 2006, Song et al. 2006, Kim et al. 2007, Nguyen et al. 2007, Poggi et al. 2007, Poulain-Godefroy \& Froguel 2007, Tsukumo et al. 2007).

A recent study showed that palmitate treatment of differentiated $\mathrm{C} 2 \mathrm{C} 12$ myotubes resulted in a time-dependent inhibition of insulin-activated signal transduction, through TLR2 activation (Senn 2006). However, the role of TLR2 in insulin resistance induced by a high-fat diet in animals has not yet been investigated.

The aims of the present study were to investigate the expression of TLR2 in muscle and white adipose tissue (WAT) of diet-induced obesity (DIO) mice, and also the effects of its inhibition, by the use of TLR2 antisense oligonucleotide (ASON), on insulin sensitivity and signaling.

\section{Research design and Methods}

\section{Materials}

Male Swiss mice were provided by the State University of Campinas Central Breeding Center (Campinas, São Paulo, 
Brazil). Human recombinant insulin was obtained from Eli Lilly. Routine reagents were purchased from Sigma Chemical, unless specified elsewhere.

\section{Animals}

All experiments were approved by the Ethics Committee at the State University of Campinas. Six-week-old Swiss mice were divided into two groups with similar body weights $(20 \pm 2 \mathrm{~g})$ and assigned to receive standard rodent chow and water ad libitum or a high-fat diet (DIO), consisting of $55 \%$ calories from fat, $29 \%$ from carbohydrate, and 16\% from protein. Mice had free access to the diets for 2 months. Body weight was measured weekly. The insulin tolerance test was performed on these mice after 8 weeks on the diets, as described previously (Perreault \& Marette 2001, Carvalho-Filho et al. 2005). Serum insulin was determined by RIA (Scott et al. 1981).

\section{TLR2 expression in gastrocnemius muscle of DIO mice}

After a period of 2 months, TLR 2 expression in muscle and WAT was analyzed. Abdominal cavities of anesthetized mice were opened and fragments of gastrocnemius muscle and WAT were excised and immediately homogenized in solubilization buffer at $4{ }^{\circ} \mathrm{C}$. Later, the samples were submitted to the direct immunoblotting process, using TLR2 antibodies (Santa Cruz Biotechnology, Inc., Santa Cruz, CA, USA).

\section{TLR2 antisense (ASON) treatment of mice}

After the period of 2 months, the mice that received DIO were divided into two groups, similar to those who received standard rodent chow: one group received an i.p. injection of $4 \cdot 0 \mathrm{nmol}$ TLR2 ASON (5'-GAG CTC GTA GCA TCC TCT-3'), and another received, by the same means, $4.0 \mathrm{nmol}$ TLR2 nonsense (NSON; $5^{\prime}$-GCT CTA TGA CTC CCA G-3'), for 4 days up to $2 \mathrm{~h}$ before killing.

\section{Insulin tolerance test (ITT)}

Immediately before the first day of TLR 2 ASON treatment, mice were submitted to an ITT, and again at 4 days after TLR2 ASON treatment. Insulin $(1.5 \mathrm{U} / \mathrm{kg})$ was administered by i.p. injection and blood samples were collected at $0,5,10,15,20,25$, and $30 \mathrm{~min}$ to determine serum glucose. The constant rate for glucose disappearance $\left(K_{\mathrm{itt}}\right)$ was calculated using the formula $0 \cdot 693 / t_{1 / 2}$. Glucose $t_{1 / 2}$ was calculated from the slope of the least-squares analysis of plasma glucose concentrations during the linear decay phase (Bonora et al. 1989).

\section{Insulin signaling}

After the fourth day of TLR2 ASON treatment, mice were anaesthetized by i.p. injection of sodium thiopental and were used $10-15 \mathrm{~min}$ later, i.e., as soon as anesthesia was assured by the loss of pedal and corneal reflexes. Five minutes after the insulin injection (1.5 U/kg i.p.), muscle and WAT were removed, minced coarsely, and homogenized immediately in extraction buffer, as described elsewhere (Thirone et al. 2004). Protein extracts obtained from the tissue were used for immunoblotting to analyze the insulin signaling.

\section{Immunoprecipitation and immunoblotting}

Abdominal cavities of anesthetized mice were opened and fragments of gastrocnemius muscle and WAT were excised and immediately homogenized in solubilization buffer at $4{ }^{\circ} \mathrm{C}(1 \%$ Triton X-100, $100 \mathrm{mmol} / 1$ Tris- $\mathrm{HCl}$ (pH 7.4), $100 \mathrm{mmol} / 1$ sodium pyrophosphate, $100 \mathrm{mmol} / 1$ sodium fluoride, $10 \mathrm{mmol} / 1$ EDTA, $10 \mathrm{mmol} / \mathrm{l}$ sodium orthovanadate, $2.0 \mathrm{mmol} / 1$ phenylmethylsulphonyl fluoride, and $0.1 \mathrm{mg}$ aprotinin $/ \mathrm{ml}$ ) with a Polytron PTA $20 \mathrm{~S}$ generator (model PT 10/35; Brinkmann Instruments, Westbury, NY, USA), operated at a maximum speed of $30 \mathrm{~s}$. Insoluble material was removed by centrifugation for $40 \mathrm{~min}$ at 11000 r.p.m. in a $70 . \mathrm{Ti}$ rotor (Beckman, Fullerton, CA, USA) at $4{ }^{\circ} \mathrm{C}$. The protein concentration of the supernatants was determined by the Bradford dye binding method (Bradford 1976). Aliquots of the resulting supernatants containing $1.0 \mathrm{mg}$ total protein were used for immunoprecipitation with antibodies against TLR 2 at $4{ }^{\circ} \mathrm{C}$ overnight, followed by SDS-PAGE, transferred to nitrocellulose membranes, and blotted with MYD88 antibodies.

In direct immunoblotting experiments, $150 \mu \mathrm{g}$ protein extracts, obtained from gastrocnemius muscle were separated by SDS-PAGE, transferred to nitrocellulose membranes, and blotted with anti-TLR, anti-phospho [Ser-307] IRS1, antiphospho [Tyr-941] IRS1, anti-NFKBIB, anti-phospho-AKT, anti-phospho-IKK $\alpha / \beta$, anti-phospho-MAPK8, and anti- $\beta$ actin (Santa Cruz Biotechnology).

In both immunoprecipitation and immunoblotting experiments, proteins were denaturated by boiling in Laemmli buffer (Laemmli 1970). For immunoblotting, the sample buffer contained $100 \mathrm{mM}$ dithiothreitol (DTT), whereas for immunoprecipitation, $50 \mathrm{mM}$ DTT was used. Specific bands were labeled with a chemioluminescence kit (Sigma) and visualization was performed by exposure of the membranes to $\mathrm{X}$-ray films. Band intensities were quantified by digital densitometry (UN-SCAN-IT gel 6.1; Silk Scientific Inc., Orem, UT, USA) of the developed autoradiographs.

\section{Homeostasis model assessment}

The degree of insulin resistance and $\beta$-cell function were estimated by the homeostasis model assessment of insulin resistance (HOMA-IR), as described by Matthews et al. (1985). HOMA-IR was calculated by the formula: fasting plasma glucose $(\mathrm{mmol} / \mathrm{l}) \times$ fasting plasma insulin $(\mathrm{mU} / \mathrm{l}) / 22 \cdot 5$.

\section{Statistical analysis}

Data are expressed as means \pm s.E.M., and the number of independent experiments is indicated. For statistical analysis, 
the groups were compared using a two-way ANOVA with the Bonferroni test for post hoc comparisons. The level of significance adopted was $P<0 \cdot 05$.

\section{Results}

\section{Animal characteristics and effect of TLR2 ASON}

The infusion of TLR2 ASON for 4 days did not change the plasma glucose or the serum insulin levels in control animals (fed standard rodent chow; Fig. 1A and B). As expected, plasma glucose and serum insulin levels were higher in DIO mice, and when these animals were treated with TLR2 ASON, there was a decrease in serum insulin levels (Fig. 1B). The glucose disappearance rate during the ITT was lower in DIO mice, reinforcing the suggestion that these animals presented insulin resistance. The administration of TLR 2 NSON to controls mice had no effect on insulin sensitivity, as measured by the ITT. In DIO mice treated with TLR2 ASON, there was an
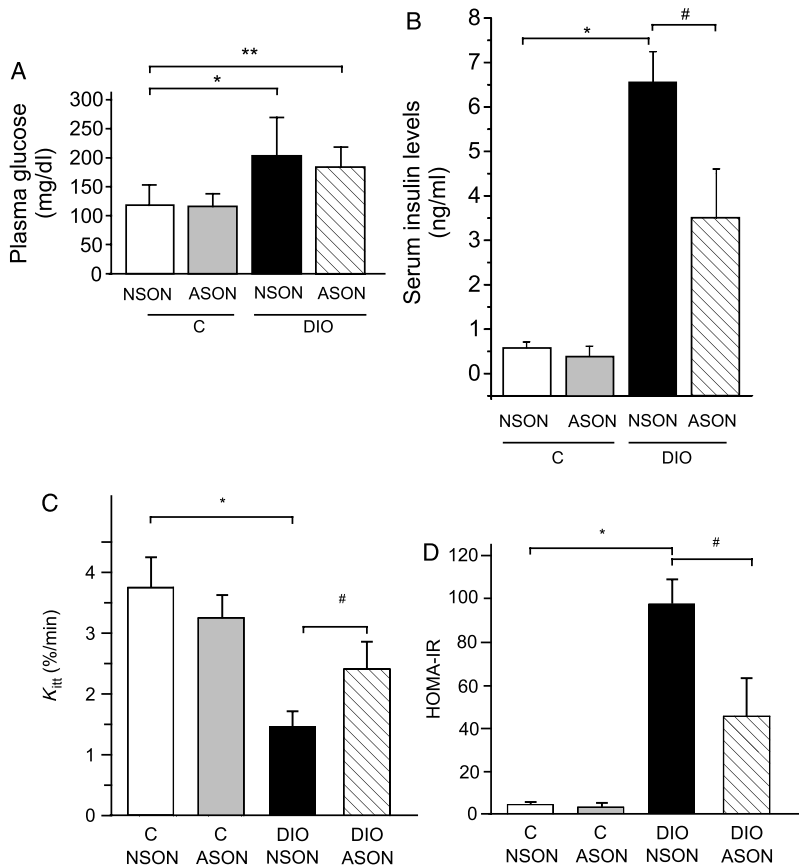

Figure 1 Plasma glucose and serum insulin levels. Bars represent mean \pm S.E.M. from six to eight mice. (A) Plasma glucose levels are higher in DIO mice compared with those fed on standard chow. However, there is no significant difference between TLR2 NSON and TLR2 ASON treatments. (B) Serum insulin levels are increased in DIO mice treated with TLR2 ASON mice. (C) Insulin sensitivity obtained from an ITT. (D) HOMA-IR, calculated by the formula: fasting plasma glucose $(\mathrm{mmol} / \mathrm{l}) \times$ fasting plasma insulin $(\mathrm{mU} / \mathrm{l}) / 22 \cdot 5 .{ }^{*} P<0 \cdot 05$ between NSON TLR2-treated control mice and NSON TLR2-treated DIO mice. ${ }^{* *} P<0 \cdot 05$ between NSON TLR2-treated control mice and TLR2 ASON-treated DIO mice. $\# P<0.05$ between TLR2 ASON- and TLR2 NSON-treated DIO mice. ITT, insulin tolerance test; HOMA-IR, homeostasis model assessment-insulin resistance. increase in glucose disappearance rate, compared with those without TLR2 ASON treatment, suggesting that inactivating TLR2 improves insulin sensitivity in these mice (Fig. 1C). This improvement is also suggested by the HOMA-IR, which is increased in DIO mice and significantly decreased in those treated with TLR2 ASON (Fig. 1D).

Effect of TLR2 ASON on TLR2 expression and downstream signaling in gastrocnemius muscle

Administration of TLR 2 ASON for 4 days reduced TLR2 expression by $50-60 \%$ in the muscle of mice fed on standard chow. An increased expression of TLR2 was seen in the gastrocnemius muscle of mice that received DIO, compared with those that received standard rodent chow (Fig. 2A). Obese animals treated with TLR2 ASON showed a marked decrease in TLR 2 expression in the muscle, indicating that the oligonucleotide was efficient for its purpose (Fig. 2A).

In order to investigate TLR 2 activation, the extracts from gastrocnemius muscle were submitted to immunoprecipitation using anti-TLR2 antibody, and then to immunoblotting using anti-MYD88 antibody, since the MYD88 protein binds to TLR2 when its ligand is recognized (Tohno et al. 2007). There was a significant decrease in TLR2/ MYD88 interaction in control mice treated with TLR2 ASON. The co-immunoprecipitation of TLR2/MYD88 was observed to increase in the muscle of DIO mice compared with control mice, but when those obese mice were treated with TLR2 ASON, the co-immunoprecipitation of TLR2/ MYD88 decreased in the muscle (Fig. 2B). These data suggest that TLR2 activation is increased in the muscle of DIO mice and decreased in those treated with TLR2 ASON.

Downstream from TLR2 activation, activation of the IKK/NFKBIB/NF- $\kappa$ B pathway occurs. The activation of IKK was investigated by the detection of its phosphorylation on serine 181. Mice fed on standard chow did not demonstrate a significant difference in IKK phosphorylation when treated with TLR2 NSON or ASON. As expected, the muscle of DIO mice presented an increased phosphorylation of IKK, while the DIO mice treated with TLR2 ASON demonstrated a decreased phosphorylation of this protein. Total IKBKB protein expression was the same in all samples (Fig. 2C).

IKK activation was also monitored using NFKBIB protein abundance. In mice fed on standard chow, no statistically significant differences were seen between the treatment with TLR2 NSON or TLR2 ASON. Our results showed a reduction in NFKBIB protein expression in the muscle of DIO mice, suggesting that there is an activation of IKK. However, after TLR2 ASON treatment, there is a complete recovery of NFKBIB expression in this tissue. Equal protein loading in the gels was confirmed by reblotting the membranes with an anti- $\beta$-actin antibody (Fig. 2D).

MAPK8 activation was determined by monitoring its phosphorylation (Thr183 and Tyr185). In mice fed a standard chow, the activation of MAPK8 was the same in both treatments, with TLR 2 NSON and with TLR2 ASON. In a 
manner similar to IKK, MAPK8 phosphorylation was increased in the muscle of mice on a DIO, but decreased in those treated with TLR2 ASON. Total MAPK8 protein expression was the same in all samples (Fig. 2E).

Effect of TLR2 ASON on insulin signaling in gastrocnemius muscle

In mice fed on standard chow, treatment with TLR2 ASON did not change insulin-induced IRS1 tyrosine phosphorylation compared with TLR2 NSON-treated mice. Insulininduced IRS1 tyrosine phosphorylation was reduced in the muscle of DIO mice, and treatment with TLR2 ASON partially reversed this alteration. Total IRS1 protein expression was the same in all samples (Fig. 3A). Insulininduced AKT phosphorylation was also reduced in the
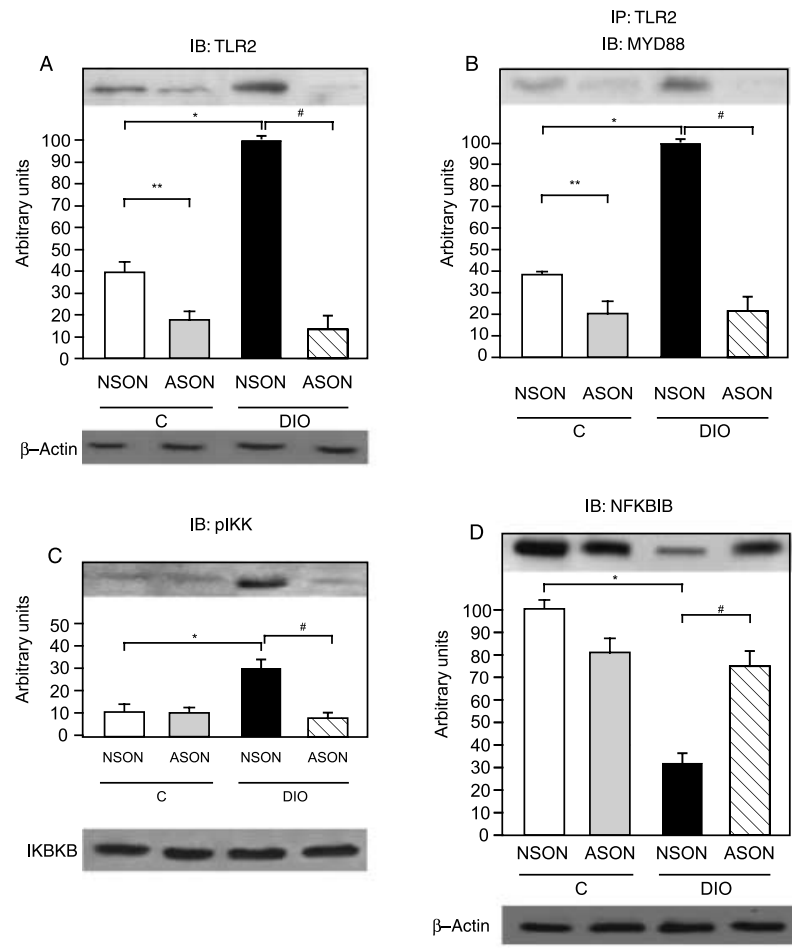

IKBKB
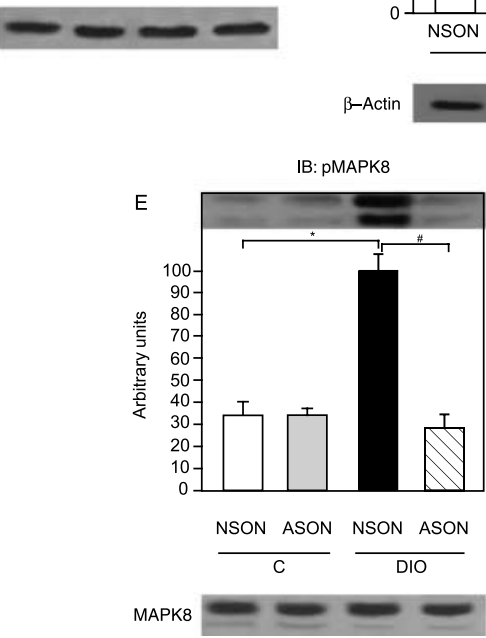

Journal of Endocrinology (2008) 199, 399-406 muscle of DIO mice. However, when these mice were treated with TLR2 ASON, there was an improvement in insulininduced AKT phosphorylation. Total AKT protein expression was the same in all samples. Equal protein loading in the gels was confirmed by reblotting the membranes with an anti- $\beta$-actin antibody (Fig. 3B).

It is known that the activation of IKK and MAPK8 can induce insulin resistance, at least in part, through phosphorylation of IRS1 at $\mathrm{Ser}^{307}$ (Hirosumi et al. 2002). Mice fed a standard chow did not show any difference in the phosphorylation of IRS1 at $\operatorname{Ser}^{307}$ when treated with TLR2 ASON. In DIO mice, there was an increase in the phosphorylation of IRS1 at $\mathrm{Ser}^{307}$ in gastrocnemius muscle, and the treatment with TLR2 ASON partially reversed this alteration (Fig. 3C).

\section{Effect of TLR2 ASON on TLR2 expression and downstream} signaling in WAT

As seen in gastrocnemius muscle, administration of TLR2 ASON for 4 days reduced TLR 2 expression by $50-60 \%$ in the WAT of mice fed on standard chow. An increased expression of TLR2 was seen in the WAT of mice that received DIO, compared with those that received standard rodent chow. Obese animals treated with TLR2 ASON showed, as expected, a decreased expression of TLR2 in WAT (Fig. 4A).

We also investigated the co-immunoprecipitation of TLR2/MYD88 in WAT and there was a significant decrease in TLR2/MYD88 interaction in control mice treated with TLR2 ASON. In DIO mice, when the samples were immunoprecipitated with TLR2 and blotted with MYD88, there was an increase in the band intensity compared with control mice. But when these mice were treated with TLR2 ASON, the co-immunoprecipitation of TLR2/MYD88 was decreased in WAT (Fig. 4B).

Figure 2 Effect of TLR2 ASON on TLR2 expression and downstream signaling in gastrocnemius muscle. Total muscle lysates were separated by western blotting and immunoblotted with the respective antibodies described in the Methods section $(n=6$ mice per group). Each bar represents the mean \pm S.E.M. of three experiments. Representative blots are shown. (A) Effects of TLR2 ASON treatment on TLR2 expression in the muscle of DIO mice. Equal protein loading in the gels was confirmed by reblotting the membranes with an anti- $\beta$-actin antibody. (B) Co-immunoprecipitation of TLR2/MYD88. (C) IKK activation detected by its phosphorylation on serine 181 . To determine the protein levels of IKBKB, the membranes were stripped and reprobed with antiIKBKB. (D) IKK activation detected by an indirect method, the expression of NFKBIB. Equal protein loading in the gels was confirmed by reblotting the membranes with an anti- $\beta$-actin antibody. (E) MAPK8 activation determined by monitoring its phosphorylation (Thr183 and Tyr185). To determine the protein levels of MAPK8, the membranes were stripped and reprobed with anti-MAPK8. ${ }^{*} P<0 \cdot 05$ between NSON TLR2-treated control mice and NSON TLR2-treated DIO mice. ${ }^{* *} P<0 \cdot 05$ between NSON TLR2 and ASON TLR2 control mice. $\# P<0.05$ between TLR2 ASON- and TLR2 NSON-treated DIO mice. 


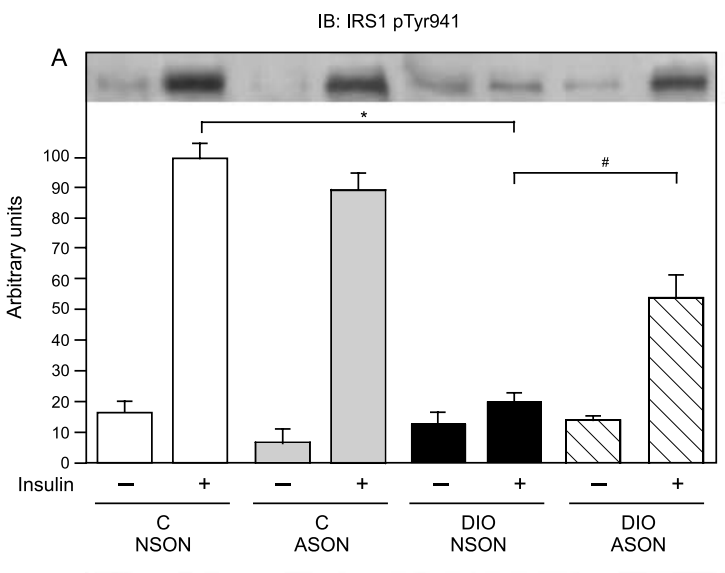

IRS1


www.endocrinology-journals.org
Mice fed a standard chow did not show a significant difference when treated with TLR2 NSON or ASON with regard to phosphorylation of IKK. As expected, WAT of DIO mice presented an increased phosphorylation of IKK, while DIO mice treated with TLR2 ASON had a decreased phosphorylation of this protein. Total IKBKB protein expression was the same in all samples (Fig. 4C). Related to NFKBIB protein expression, in mice fed on standard chow, no statistically significant differences were seen between the treatment with TLR2 NSON or TLR2 ASON. Our results showed a reduction in NFKBIB protein expression in the WAT of DIO mice, suggesting that there is an activation of IKK. However, after TLR2 ASON treatment, there was a complete recovery of NFKBIB expression in this tissue. Equal protein loading in the gels was confirmed by reblotting the membranes with an anti- $\beta$-actin antibody (Fig. 4D).

As seen in muscle, in mice fed on standard chow, the phosphorylation of MAPK8 did not change with TLR2 ASON treatment. On the other hand, MAPK8 phosphorylation was increased in the WAT of DIO mice, but decreased in those treated with TLR2 ASON. Total MAPK8 protein expression was the same in all samples (Fig. 4E).

\section{Effect of the inhibition of TLR2 on insulin signaling in WAT}

In mice fed on standard chow, treatment with TLR2 ASON did not change insulin-induced IRS1 tyrosine phosphorylation. Insulin-induced IRS1 tyrosine phosphorylation was reduced in the WAT of DIO mice, and treatment with TLR2 ASON partially reversed this alteration. Total IRS1 protein expression was the same in all samples (Fig. 5A). Insulin-induced AKT phosphorylation was also reduced in the WAT of DIO mice. However, when these mice were treated with TLR2 ASON, there was an improvement in insulin-induced AKT phosphorylation. Total AKT protein expression was the same in all samples. Equal protein loading in the gels was confirmed by reblotting the membranes with an anti- $\beta$-actin antibody (Fig. $5 \mathrm{~B}$ ).

The phosphorylation of IRS1 at $\operatorname{Ser}^{307}$ in the WAT of mice fed a standard chow and treated with TLR2 ASON did not differ from that in TLR2 NSON-treated mice. As expected in

Figure 3 Effect of the inhibition of TLR2 on insulin sensitivity in gastrocnemius muscle. Total muscle lysates were separated by western blotting and immunoblotted with the respective antibodies described in the Methods section ( $n=6$ mice per group). Each bar represents the mean \pm S.E.M. of three experiments. Representative blots are shown. (A) Insulin-induced phosphorylation of IRS1 (Tyr941). To determine the protein levels of IRS1, the membranes were stripped and reprobed with anti-IRS1. (B) Insulin-induced serine phosphorylation of AKT. To determine the protein levels of AKT, the membranes were stripped and reprobed with anti-AKT. Equal protein loading in the gels was confirmed by reblotting the membranes with an anti- $\beta$-actin antibody. (C) Ser ${ }^{307}$ phosphorylation of IRS1. Equal protein loading in the gels was confirmed by reblotting the membranes with an anti- $\beta$-actin antibody. ${ }^{*} P<0 \cdot 05$ between NSON TLR2-treated control mice and NSON TLR2treated DIO mice. \#P<0.05 between TLR2 ASON- and TLR2 NSON-treated DIO mice. 
the WAT of DIO mice, there was an increase in the phosphorylation of IRS1 at $\mathrm{Ser}^{307}$, and the treatment with TLR2 ASON partially reversed this alteration (Fig. 5C).

\section{Discussion}

The consumption of a high-fat diet is one of the major causes of obesity and insulin resistance. However, the molecular mechanism by which DIO leads to insulin resistance and a state of abnormal inflammatory response are not completely understood (Kadowaki et al. 2003, Barreiro et al. 2004, Bray 2004, Araujo et al. 2005, Prada et al. 2005, Tsukumo et al. 2007). Our data showed an increased expression of TLR 2 in the muscle and WAT of DIO mice, and treatment with TLR2 ASON improves the insulin resistance of these mice, suggesting that


Journal of Endocrinology (2008) 199, 399-406
TLR2 is an important modulator in the crosstalk between inflammation and metabolic pathway in DIO. However, in mice fed on standard chow, the inhibition of TLR 2 did not cause an improvement in insulin sensitivity. This is probably due to the fact that TLR 2 has a role in insulin resistance in obesity, but does not have a central role in the control of insulin sensitivity and signaling in physiological conditions.

A recent study showed that palmitate treatment of differentiated C2C12 myotubes results in a time-dependent inhibition of insulin-activated signal transduction, specifically tyrosine phosphorylation of the insulin receptor and the phosphorylation of AKT. Palmitate also induced the production of significant amounts of IL6 and the phosphorylation of p38 and MAPK8. Additionally, palmitate induced a rapid activation of TLR 2 signal transduction in a time-dependent manner. Treatment of cells with a monoclonal antagonist antibody anti-TLR2 blocked the subsequent induction of IL6 production and restored the insulin-induced AKT phosphorylation (Senn 2006). Therefore, cell culture data provide convincing evidence that fatty acids leads to insulin resistance at least in part through TLR2.

Our data show that, in the muscle and WAT of DIO mice, there is an increase in TLR2 expression, a modulation that might have a role in insulin resistance in these animals. Upon stimulation, TLR recruits IL1R1-associated protein kinases via adaptor protein MYD88 and finally induces the activation of nuclear factor- $\kappa \mathrm{B}$ and mitogen-activated protein kinases, as well as the expression of inflammatory cytokines (Aderem \& Ulevitch 2000, Heldwein \& Fenton 2002, Akira \& Sato 2003). Our data demonstrate that, in the muscle and WAT from DIO mice, MYD88 associates with the TLR2, activating downstream kinases such as IKK, weakening insulin signal transduction, and reducing the glucose disappearance rate. The reduced insulin sensitivity of DIO mice, as demonstrated by reduced glucose disappearance rate, high insulin levels, and higher HOMA-IR, was improved when these mice were treated with TLR2 ASON.

Figure 4 Effect of TLR2 ASON on TLR2 expression and downstream signaling in WAT. Total white adipose tissue lysates were separated by western blotting and immunoblotted with the respective antibodies described in the Methods section ( $n=6$ mice per group). Each bar represents the mean \pm S.E.M. of three experiments. Representative blots are shown. (A) Effects of TLR2 ASON treatment on TLR2 expression in the WAT of DIO mice. Equal protein loading in the gels was confirmed by reblotting the membranes with an anti$\beta$-actin antibody. (B) Co-immunoprecipitation of TLR2/MYD88. (C) IKK activation detected by its phosphorylation on serine 181 . To determine the protein levels of IKBKB, the membranes were stripped and reprobed with anti-IKBKB. (D) IKK activation detected by an indirect method, the expression of NFKBIB. Equal protein loading in the gels was confirmed by reblotting the membranes with an anti- $\beta$-actin antibody. (E) MAPK8 activation determined by monitoring its phosphorylation (Thr183 and Tyr185). To determine the protein levels of MAPK8, the membranes were stripped and reprobed with anti-MAPK8. ${ }^{*} P<0.05$ between NSON TLR2-treated control mice and NSON TLR2-treated DIO mice. $* * P<0 \cdot 05$ between NSON TLR2 and ASON TLR2 control mice. $\# P<0 \cdot 05$ between TLR2 ASON- and TLR2 NSON-treated DIO mice. 


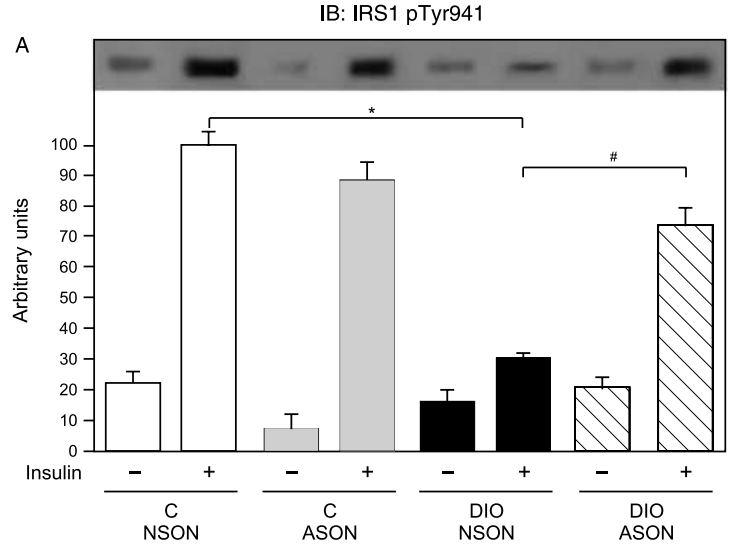

IRS1
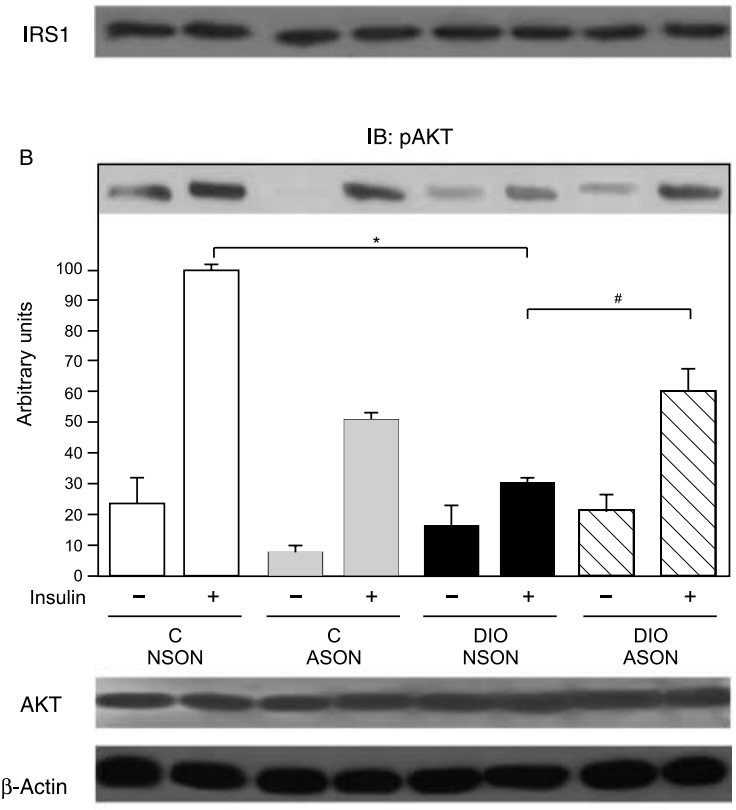

IB: IRS1 pSer307

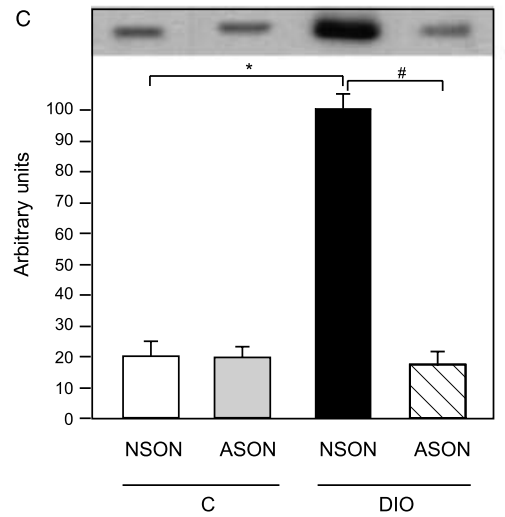

$\beta$-Actin
The blunted insulin-stimulated IRS1 tyrosine (941) phosphorylation and phosphorylation of AKT in the muscle of DIO mice was restored in the DIO mice treated with TLR2 ASON, providing a biochemical correlate for increased in vivo insulin sensitivity. Serine phosphorylation of IRS1 has been proposed as a general mechanism of functional inhibition of the IRS1 protein, and $\mathrm{Ser}^{307}$ phosphorylation has become a molecular indicator of insulin resistance (Aguirre et al. 2002, Gao et al. 2002, Hirosumi et al. 2002, Lee et al. 2003). Ser ${ }^{307}$ phosphorylation was induced by the high-fat diet in the muscles and WAT of DIO mice, accompanied by a reduction in insulin-induced IRS1 tyrosine (941) phosphorylation levels. This regulation of IRS1, induced by the DIO, was rescued in the DIO mice treated with TLR2 ASON.

$\mathrm{Ser}^{307}$ is reported to be a phosphoacceptor of MAPK8 and IKK (Aguirre et al. 2002, Gao et al. 2002) and, as previously described (Yuan et al. 2001, Hirosumi et al. 2002), our results also show that both kinases are activated the in tissues of DIO controls. It is well known that the activation of TLR 2 induces a complex signaling pathway that activates IKK and MAPK8 (Takeda et al. 2003). Our data, demonstrating that the inhibition of TLR2 expression rescues the tissues from the activation of IKK and MAPK8 and from the insulin resistance, suggest that TLR2 is a key modulator in the crosstalk between inflammatory and metabolic pathways. However, the fact that the activation of IKK leads to the insulin resistance is not uniformly observed (Polkinghorne et al. 2008).

In the past 2 years, different studies showed that TLR 4 has an important role in obesity-induced insulin resistance, and that mice with a loss-of-function mutation or knockout for TLR4 are protected from diet-induced insulin resistance (Senn 2006, Shi et al. 2006, Song et al. 2006, Kim et al. 2007, Nguyen et al. 2007, Poggi et al. 2007, Poulain-Godefroy \& Froguel 2007, Tsukumo et al. 2007). Our data show that TLR2 may also have a role in the interface of subclinical inflammation and insulin resistance in DIO mice.

In summary, our data, showing that the inhibition of TLR2 expression rescues the cells from the activation of IKK and MAPK8 and insulin resistance in the DIO mice, indicate that TLR2 is a key modulator in the crosstalk between

Figure 5 Effect of the inhibition of TLR2 on insulin sensitivity in WAT. Total white adipose tissue lysates were separated by western blotting and immunoblotted with the respective antibodies described in the Methods section ( $n=6$ mice per group). Each bar represents the mean \pm s.E.M. of three experiments. Representative blots are shown. (A) Insulin-induced phosphorylation of IRS1 (Tyr941). To determine the protein levels of IRS1, the membranes were stripped and reprobed with anti-IRS1. (B) Insulin-induced serine phosphorylation of AKT. To determine the protein levels of AKT, the membranes were stripped and reprobed with anti-AKT. Equal protein loading in the gels was confirmed by reblotting the membranes with an anti- $\beta$-actin antibody. (C) Ser ${ }^{307}$ phosphorylation of IRS1. Equal protein loading in the gels was confirmed by reblotting the membranes with an anti- $\beta$-actin antibody. ${ }^{*} P<0 \cdot 05$ between control mice and DIO mice. $\# P<0 \cdot 05$ between TLR2 ASON- and TLR2 NSON-treated DIO mice. 
inflammatory and metabolic pathways. We, therefore, suggest that a selective interference with TLR 2 presents an attractive opportunity for the treatment of obesity, insulin resistance, and type 2 diabetes.

\section{Declaration of interest}

The authors declare that there is no conflict of interest that would prejudice the impartiality of this scientific work.

\section{Funding}

These studies were supported by grants from Fundação de Amparo à Pesquisa do Estado de São Paulo (FAPESP) and Conselho Nacional de desenvolvimento científico e tecnológico (CNPq).

\section{References}

Aderem A \& Ulevitch RJ 2000 Toll-like receptors in the induction of the innate immune response. Nature 406 782-787.

Aguirre V, Werner ED, Giraud J, Lee YH, Shoelson SE \& White MF 2002 Phosphorylation of Ser307 in insulin receptor substrate-1 blocks interactions with the insulin receptor and inhibits insulin action. Journal of Biological Chemistry 277 1531-1537.

Akira S \& Sato S 2003 Toll-like receptors and their signaling mechanisms. Scandinavian Journal of Infectious Diseases 35 555-562.

Araujo EP, De Souza CT, Gasparetti AL, Ueno M, Boschero AC, Saad MJ \& Velloso LA 2005 Short-term in vivo inhibition of insulin receptor substrate1 expression leads to insulin resistance, hyperinsulinemia, and increased adiposity. Endocrinology 146 1428-1437.

Barreiro GC, Prattali RR, Caliseo CT, Fugiwara FY, Ueno M, Prada PO, Velloso LA, Saad MJ \& Carvalheira JB 2004 Aspirin inhibits serine phosphorylation of IRS-1 in muscle and adipose tissue of septic rats. Biochemical and Biophysical Research Communications $320992-997$.

Bonora E, Moghetti P, Zancanaro C, Cigolini M, Querena M, Cacciatori V, Corgnati A \& Muggeo M 1989 Estimates of in vivo insulin action in man: comparison of insulin tolerance tests with euglycemic and hyperglycemic glucose clamp studies. Journal of Clinical Endocrinology and Metabolism 68 374-378.

Bradford MM 1976 A rapid and sensitive method for the quantitation of microgram quantities of protein utilizing the principle of protein-dye binding. Analytical Biochemistry 72 248-254.

Bray GA 2004 Medical consequences of obesity. Journal of Clinical Endocrinology and Metabolism 89 2583-2589.

Carvalho-Filho MA, Ueno M, Hirabara SM, Seabra AB, Carvalheira JB, de Oliveira MG, Velloso LA, Curi R \& Saad MJ 2005 S-nitrosation of the insulin receptor, insulin receptor substrate 1 , and protein kinase B/Akt: a novel mechanism of insulin resistance. Diabetes 54 959-967.

Gao Z, Hwang D, Bataille F, Lefevre M, York D, Quon MJ \& Ye J 2002 Serine phosphorylation of insulin receptor substrate 1 by inhibitor kappa B kinase complex. Journal of Biological Chemistry 277 48115-48121.

Heldwein KA \& Fenton MJ 2002 The role of Toll-like receptors in immunity against mycobacterial infection. Microbes and Infection 4 937-944.

Hirosumi J, Tuncman G, Chang L, Gorgun CZ, Uysal KT, Maeda K, Karin M \& Hotamisligil GS 2002 A central role for JNK in obesity and insulin resistance. Nature 420 333-336.

Kadowaki T, Hara K, Yamauchi T, Terauchi Y, Tobe K \& Nagai R 2003 Molecular mechanism of insulin resistance and obesity. Experimental Biology and Medicine 228 1111-1117.

Kim F, Pham M, Luttrell I, Bannerman DD, Tupper J, Thaler J, Hawn TR, Raines EW \& Schwartz MW 2007 Toll-like receptor-4 mediates vascular inflammation and insulin resistance in diet-induced obesity. Circulation Research 100 1589-1596.

Laemmli UK 1970 Cleavage of structural proteins during the assembly of the head of bacteriophage T4. Nature 227 680-685.
Lee YH, Giraud J, Davis RJ \& White MF 2003 c-Jun N-terminal kinase (JNK) mediates feedback inhibition of the insulin signaling cascade. Journal of Biological Chemistry 278 2896-2902.

Matthews DR, Hosker JP, Rudenski AS, Naylor BA, Treacher DF \& Turner RC 1985 Homeostasis model assessment: insulin resistance and beta-cell function from fasting plasma glucose and insulin concentrations in man. Diabetologia 28 412-419.

Nguyen MT, Favelyukis S, Nguyen AK, Reichart D, Scott PA, Jenn A, LiuBryan R, Glass CK, Neels JG \& Olefsky JM 2007 A subpopulation of macrophages infiltrates hypertrophic adipose tissue and is activated by free fatty acids via Toll-like receptors 2 and 4 and JNK-dependent pathways. Journal of Biological Chemistry 282 35279-35292.

Perreault M \& Marette A 2001 Targeted disruption of inducible nitric oxide synthase protects against obesity-linked insulin resistance in muscle. Nature Medicine 7 1138-1143.

Poggi M, Bastelica D, Gual P, Iglesias MA, Gremeaux T, Knauf C, Peiretti F, Verdier M, Juhan-Vague I, Tanti JF et al. 2007 C3H/HeJ mice carrying a toll-like receptor 4 mutation are protected against the development of insulin resistance in white adipose tissue in response to a high-fat diet. Diabetologia 50 1267-1276.

Polkinghorne E, Lau Q, Cooney GJ, Kraegen EW \& Cleasby ME 2008 Local activation of the IkappaK-NF-kappaB pathway in muscle does not cause insulin resistance. American Journal of Physiology. Endocrinology and Metabolism 294 E316-E325.

Poulain-Godefroy O \& Froguel P 2007 Preadipocyte response and impairment of differentiation in an inflammatory environment. Biochemical and Biophysical Research Communications 356 662-667.

Prada PO, Zecchin HG, Gasparetti AL, Torsoni MA, Ueno M, Hirata AE, Corezola do Amaral ME, Hoer NF, Boschero AC \& Saad MJ 2005 Western diet modulates insulin signaling, c-Jun N-terminal kinase activity, and insulin receptor substrate-1ser307 phosphorylation in a tissue-specific fashion. Endocrinology 146 1576-1587.

Scott AM, Atwater I \& Rojas E 1981 A method for the simultaneous measurement of insulin release and B cell membrane potential in single mouse islets of Langerhans. Diabetologia 21 470-475.

Senn JJ 2006 Toll-like receptor-2 is essential for the development of palmitateinduced insulin resistance in myotubes. Journal of Biological Chemistry 281 26865-26875.

Shi H, Kokoeva MV, Inouye K, Tzameli I, Yin H \& Flier JS 2006 TLR 4 links innate immunity and fatty acid-induced insulin resistance. Journal of Clinical Investigation 116 3015-3025.

Song MJ, Kim KH, Yoon JM \& Kim JB 2006 Activation of Toll-like receptor 4 is associated with insulin resistance in adipocytes. Biochemical and Biophysical Research Communications 346 739-745.

Takeda K \& Akira S 2004 TLR signaling pathways. Seminars in Immunology 16 3-9.

Takeda K, Kaisho T \& Akira S 2003 Toll-like receptors. Annual Review of Immunology 21 335-376.

Thirone AC, Carvalheira JB, Hirata AE, Velloso LA \& Saad MJ 2004 Regulation of Cbl-associated protein/Cbl pathway in muscle and adipose tissues of two animal models of insulin resistance. Endocrinology 145 281-293.

Tohno M, Shimazu T, Aso H, Kawai Y, Saito T \& Kitazawa H 2007 Molecular cloning and functional characterization of porcine MyD88 essential for TLR signaling. Cellular \& Molecular Immunology 4 369-376.

Tsukumo DM, Carvalho-Filho MA, Carvalheira JB, Prada PO, Hirabara SM, Schenka AA, Araujo EP, Vassallo J, Curi R, Velloso LA et al. 2007 Lossof-function mutation in Toll-like receptor 4 prevents diet-induced obesity and insulin resistance. Diabetes 56 1986-1998.

Yuan M, Konstantopoulos N, Lee J, Hansen L, Li ZW, Karin M \& Shoelson SE 2001 Reversal of obesity- and diet-induced insulin resistance with salicylates or targeted disruption of Ikkbeta. Science 293 1673-1677.

Received in final form 6 September 2008

Accepted 8 September 2008

Made available online as an Accepted Preprint 11 September 2008 